\title{
TERAPI LATIHAN FISIK SEBAGAI TATA LAKSANA CEDERA SPRAIN PERGELANGAN KAKI BERULANG: LAPORAN KASUS
}

\author{
Alvin Wiharja, Sri Nilawati \\ Fakultas Kedokteran \\ Universitas Indonesia
}

\begin{abstract}
Ankle sprain is a common injury that often occurs during exercise (Terada et al., 2013; Kaminski et al., 2013; Ktaiche et al., 2015; Lin et al., 2012). Clinicians have been seeking various ways to deal with this injury. There are a variety of treatment options and strategies to manage this health issues in patients (Kaminski et al., 2013; Terada et al., 2013). However, the most effective therapy in these injuries still has not be determined (Terada et al., 2013).

Firstable, by determining the research question: "Which is the most appropriate therapy for an ankle sprain injury?" Then conducted a systematic review to gather the latest scientific evidence in order to help in choosing the appropriate the treatment and prevention of ankle sprain injury. Obtained two manuscripts that discuss the similar issue, entitled "Intervention for Increasing Ankle Theurapetic Dorsoflexion After Ankle sprain: A Systematic Review" and "National Athletic Trainers' Associations Position Statement: Conservative Management and Prevention of Ankle sprains in Athletes". In the manuscript describes a combination of stretching exercises, strength training, exercise therapy propioception in exercise is the most effective procedures on managing and preventing recurrent ankle sprains (Kaminski et al., 2013; Terada et al., 2013).

We can conclude that the treatment of choice based on scientific searches in ankle sprain injury patients is exercise therapy. However, it should be noted on the prescription of exercise will vary according to the conditions and circumstances of each patients.
\end{abstract}

Keywords: ankle sprain, exercise therapy, recurrent injury, prevention program

\begin{abstract}
ABSTRAK
Cedera sprain pada pergelangan kaki merupakan cedera yang sering terjadi pada saat melakukan latihan fisik (Terada et al., 2013; Kaminski et al., 2013; Ktaiche et al., 2015; Lin et al., 2012). Para klinisi telah mengupayakan berbagai metode tata laksana untuk menangani cedera ini. Terdapat keanekaragaman pilihan terapi dan strategi penanganan masalah kesehatan pada pasien dengan keluhan nyeri pada pergelangan pasien (Kaminski et al., 2013; Terada et al., 2013). Namun demikian, kombinasi ataupun pilihan terapi yang paling efektif pada cedera ini masih belum dapat ditentukan secara pasti (Terada et al., 2013).

Langkah pertama yang dilakukan adalah menentukan pertanyaan penelitian, yaitu: "Jenis terapi pilihan apakah yang sesuai untuk cedera sprain pergelangan kaki?" Kemudian dilakukan systematic review untuk mengumpulkan bukti-bukti ilmiah terbaru agar membantu menjelaskan tata laksana dan pencegahan cedera sprain pergelangan kaki. Didapatkan 2 manuskrip yang membahas isu yang hampir serupa dengan berjudul "Theurapetic Intervention for Increasing Ankle Dorsoflexion After Ankle Sprain: A Systematic Review" dan "National Athletic Trainers' Associations Position Statement: Conservative Management and Prevention of Ankle Sprains in Athletes". Pada manuskrip tersebut menjabarkan kombinasi latihan peregangan, latihan kekuatan, latihan propioseptif dalam terapi latihan fisik sebagai
\end{abstract}


prosedur tata laksana dan pencegahan cedera sprain pergelangan kaki berulang yang paling efektif (Kaminski et al., 2013; Terada et al., 2013).

Dapat disimpulkan terapi pilihan berdasarkan penelusuran ilmiah pada pasien dengan keluhan cedera sprain pada pergelangan kaki adalah terapi latihan fisik. Namun perlu diperhatikan pada peresepan latihan fisik setiap pasien akan berbeda disesuaikan dengan kondisi dan keadaan masing-masing individunya.

Kata kunci: sprain pergelangan kaki, terapi latihan fisik, cedera berulang, program pencegahan

\section{PENDAHULUAN}

Cedera sprain pada pergelangan kaki merupakan cedera yang sering terjadi pada saat melakukan latihan fisik (Terada et al., 2013; Kaminski et al., 2013; Ktaiche et al., 2015; Lin et al., 2012). Angka cedera tercatat lebih tinggi pada olahraga yang berintensitas tinggi, berkecepatan tinggi dan jenis olahraga yang pergerakannya dinamis (Lin et al., 2012). Didapatkan bahwa sekitar $28 \%$ atlet pelajar mengalami cedera sprain pergelangan kaki berulang. Persentase ini lebih besar jika dibandingan dengan cedera yang lain. Sekitar 74\%, yang mengalami cedera berulang ini nampak menyerah dan tidak melanjutkan terapi hingga tuntas (Bowker et al., 2016).

Cedera sprain pada pergelangan kaki dapat menyebabkan kerusakan pada struktur ligamen, di sekitarnya. Kejadian cedera sprain pergelangan kaki yang kerap kali terjadi dapat berujung pada perburukan dan dikenal sebagai instabilitas pergelangan kaki kronis/chronic ankle instability (CAI) (Hall et al., 2015; Gribble et al., 2014).

Namun demikian, kombinasi ataupun pilihan terapi yang paling efektif untuk penanganan cedera ini masih belum dapat ditentukan secara pasti (Terada et al., 2013). Oleh karena itu, penulis menyusun laporan kasus ini sebagai bahan pertimbangan pemilihan terapi yang sesuai dan dapat menjadi masukan untuk sejawat lain yang mendapatkan kasus serupa.

\section{LAPORAN KASUS}

Pasien seorang laki-laki berumur 27 tahun datang ke klinik spesialis kedokteran olahraga dengan nyeri pada pergelangan kaki kanan yang dirasakan sejak 1 
bulan yang lalu. Pada anamnesis didapatkan bahwa nyeri tersebut timbul setelah kaki kanan terkilir saat bermain bola. Tepatnya, saat mendarat dengan keadaan pergelangan kaki menekuk ke dalam setelah menendang bola yang datang ke arah pasien terjadi secara mendadak. Lokasi nyeri terdapat pada sisi luar di bawah mata kaki pada daerah pergelangan kaki sebelah kanan. Saat terjadinya cedera, pasien masih dapat jinjit serta berjalan walaupun dalam keadaan nyeri. Pada awalnya, nyeri terasa dengan skala VAS 8 dari 10 disertai bengkak dan kemerahan. Sekarang ini nyeri sudah dirasakan berkurang dengan skala VAS 4 dari 10.

Sebelum datang ke klinik spesialis kedokteran olahraga, pasien sudah melakukan beberapa usaha berobat. Selain mengompres es, usaha berobat lainnya yang dilakukan pasien adalah kembali ke klinik fisioterapi untuk masalah cedera tersebut. Di klinik fisioterapi tersebut, pasien diberikan: kompres es, terapi "getar", ultrasound dan diistirahatkan. Pasien tidak berkonsultasi ke dokter ataupun mengonsumsi obat-obatan tertentu.

Pada 3 bulan yang lalu, pasien juga mengalami cedera non-kontak saat bermain bola. Tepatnya, pasien jatuh saat tersandung bola dan pergelangan kaki kirinya terkilir. Lokasi nyeri timbul pada sisi luar di bawah mata kaki pada daerah pergelangan kaki sebelah kiri. Pada fase awal terjadinya cedera, nyeri dirasakan dengan skala VAS 10 dari 10, disertai bengkak dan kemerahan. Pasien mengalami kesulitan berjalan dan beraktivitas sehari-hari.

Sejak cedera ankle kiri yang terjadi 3 bulan yang lalu, telah melakukan kompres es, berobat ke klinik fisioterapi untuk mendapatkan terapi "getar" dan terapi ultrasound untuk pergelangan kaki kirinya tersebut. Terapi tersebut dijalankan oleh pasien setiap 2 kali seminggu, selama 6 minggu. Selama menjalani terapi nyeri yang dirasakan pasien berkurang dari skala VAS 10 menjadi skala VAS 0 , namun pasien masih merasa pergelangan kakinya 
mengganjal saat melakukan gerakan pointing dengan kaki kirinya. 6 minggu yang lalu pasien memutuskan untuk men-coba bermain bola kembali. Setelah 2 minggu, pasien mengalami cedera pergelangan kaki.

Pasien mengaku bahwa kerap kali mengalami cedera pergelangan kaki kanan dan kiri yang berulang. Cedera tersebut mulai dialami sejak berada di bangku SMP. Pasien mengaku bahwa cedera yang dialaminya tersebut semakin sering dirasakan dengan berjalannya waktu. Jika diambil rerata, menurut pasien, dia dapat mengalami cedera tersebut kurang lebih $2 \mathrm{x}$ per tahunnya. Pada awalnya pasien menganggap bahwa cedera tersebut dapat sembuh sendiri dan tidak perlu penanganan yang serius. Biasanya apabila pasien mengalami cedera tersebut, dia mengistirahatkan diri kurang lebih selama 3 bulan. Bila kondisi sudah dirasakan membaik, pasien kembali melakukan latihan fisik seperti sediakala.
Pasien tersebut secara rutin melakukan latihan fisik kardiorespiratori sebanyak 2-3 kali seminggu. Latihan peregangan dilakukan sesudah dan sebelum sesi latihan larinya. Dia tidak melakukan latihan beban atau latihan penguatan lainnya.

\section{Pemeriksaan Fisik}

1. Inspeksi: tidak terlihat kemerahan atau bengkak di kedua pergelangan kaki pasien. Bentuk dan struktur tungkai kanan dan kiri pasien relatif sama.

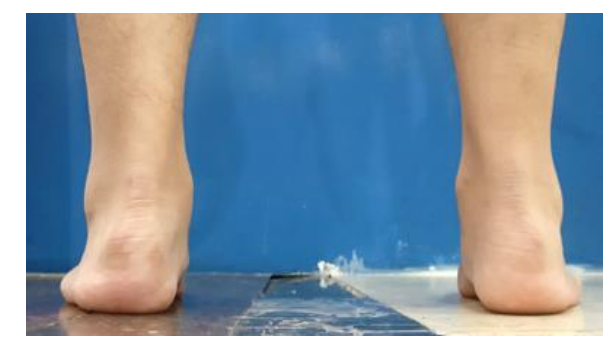

Gambar 1. Pergelangan kaki pasien tampak belakang

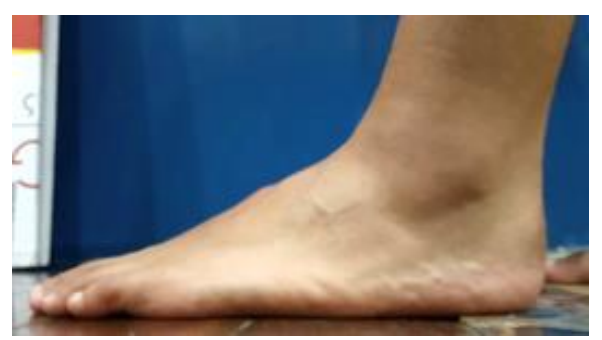

Gambar 2. Pergelangan kaki kiri tampak lateral

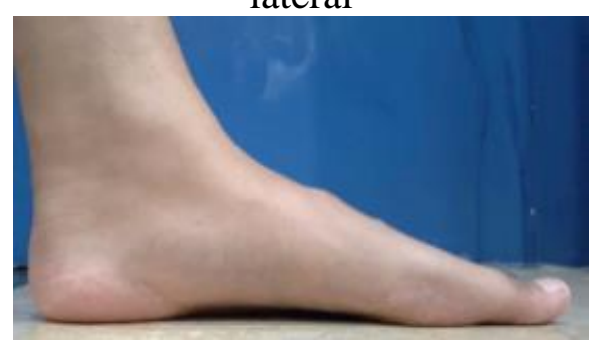


Gambar 3. Pergelangan kaki kiri tampak medial

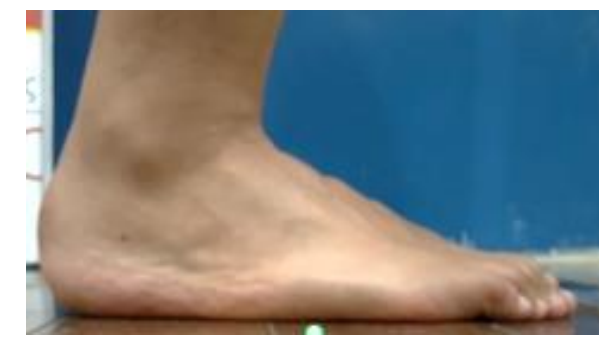

Gambar 4. Pergelangan kaki kanan tampak lateral

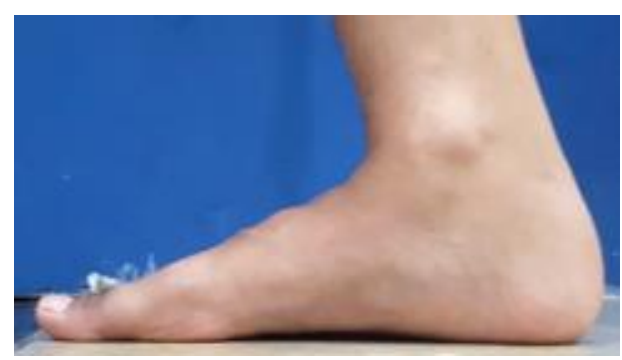

Gambar 5. Pergelangan kaki kanan tampak medial

2. Palpasi: nyeri tekan di daerah pergelangan kaki kanan dan kiri lateral dengan skala nyeri (VAS) 4-5 untuk pergelangan kaki kanan dan skala nyeri (VAS) 1-2 untuk pergelangan kaki kiri. Sedangkan pada pergerakan (move), ruang lingkup sendi pergelangan kaki kanan dan kaki kiri pasien masih dalam batas normal. Namun dirasakan adanya nyeri saat gerakan inversi pada ruang lingkup sendi maksimal pergelangan kaki kanan.

Untuk menyingkirkan diagnosis banding lainnya dilakukan pemeriksa- an lain, yaitu: pemeriksaan lingkar pergelangan kaki (hasil dalam batas normal), pemeriksaan leg length discrepancy (hasil dalam batas normal), pemeriksaan wet foot test dan pemeriksaan anterior drawer test ankle, tidak ditemukan adanya kelainan.

\section{Diagnosis kerja}

Ankle sprain kronis dekstra.

\section{Ilustrasi kasus}

Penegakan diagnosis pada pasien ini berdasarkan anamnesis dan pemeriksaan fisik. Pada anamnesis didapatkan pasien mengalami cedera pada pergelangan kaki kanan yang diakibatkan oleh trauma nonkontak sewaktu penderita melakukan bermain bola. Dari hasil analisis anamnesis didapatkan bahwa mekanisme terjadinya trauma ketika kaki pasien mendarat dengan keadaan pergelangan kaki kanan inversi ke dalam setelah menendang bola yang datang secara mendadak. Pada pemeriksaan fisik tidak didapatkan tandatanda inflamasi akut secara inspeksi, namun penderita masih merasakan nyeri 
pada saat palpasi dan pergerakan. Tidak ditemukan juga diskontinuitas totalis pada struktur yang mengalami cedera melalui pemeriksaan fisik pergerakan dan tes khusus. Dari pemeriksaan dapat disimpulkan bahwa cedera yang dialami penderita adalah cedera sprain pergelangan kaki derajat 1-2 subakut dekstra dan sinistra.

\section{Diskusi}

Para klinisi telah mengupayakan berbagai metode tata laksana untuk menangani cedera ini. Terdapat keanekaragaman pilihan terapi dan strategi penanganan masalah kesehatan pada pasien dengan keluhan nyeri pada pergelangan pasien. Pilihan terapi yang sesuai dapat memberikan hasil yang maksimal dalam tata laksana cedera tersebut. Mulai dari latihan peregangan, elektroterapi, ultrasound (Kaminski et al., 2013; Terada et al., 2013).

Langkah pertama yang dilakukan untuk menentukan tata laksana yang sesuai adalah dengan melakukan systematic review. Didapatkan 2 manuskrip dari perang- kat pencarian Proquest yang membahas isu yang hampir serupa dengan judul "Theurapetic Intervention for Increasing Ankle Dorsoflexion After Ankle Sprain: A Systematic Review" dan "National Athletic Trainers' Associations Position Statement: Conservative Management and Prevention of Ankle Sprains in Athletes". Kedua manuskrip tersebut berisi tatacara terapi cedera strain pergelangan kaki yang meliputi: latihan peregangan, latihan kekuatan, latihan propioseptif dan program pencegahan cedera sprain pergelangan kaki berulang. Terapi latihan fisik dinyatakan sebagai prosedur tata laksana yang paling efektif dibandingkan dengan terapi lainnya (Kaminski et al., 2013; Terada et al., 2013).

Pada manuskrip pertama hasil karya Terada M. et al. yang merupakan suatu kajian sistematis, terdapat 9 studi lain yang dianalisis lebih dalam. Studi-studi tersebut dikelompokan dalam beberapa metode tata laksana sprain pergelangan kaki. Berikut ini pengelompokan metode-metode terse- 
but (Terada et al., 2013: 1) Terapi manual,

2) Terapi modalitas, 3) Terapi latihan fisik, dan 4) Intervensi psikologis.

Pada manuskrip ini dikemukakan bahwa mengembalikan ruang lingkup sendi setelah cedera sprain pergelangan kaki sangat penting untuk dilakukan. Oleh karena dengan mengembalikan ruang lingkup sendi ke jangkauan normal maka risiko terjadinya cedera berulang akan menurun. Bukan hanya itu, pengembalian kemampuan fungsional pergelangan kaki lebih cepat tercapai. Berdasarkan kondisi unik masing-masing pasien, klinisi perlu menentukan tata laksana yang paling sesuai untuk diterapkan. Masing-masing pasien mungkin memiliki pilihan terapi yang berbeda satu sama lain (Terada et al., 2013). Satu hal yang perlu diingat, bahwa rasa nyeri bukan sebagai indikator tunggal dalam menentukan kesembuhan dan kesiapan seorang pasien untuk dapat berolahraga kembali. Rasa nyeri akan hilang dalam jangka waktu yang lebih cepat dibandingkan dengan masa penyembuhan jaringan dan struktur yang rusak akibat cedera (Silbernagel et al., 2007).

Sedangkan pada pustaka kedua, pustaka ini membahas lengkap cedera sprain pergelangan kaki, mulai dari diagnosis, terapi bahkan hingga langkah-langkah preventif. Kelebihan pustaka milik Kaminski T.W. et al. adalah pengelompokan kekuatan rekomendasi dari masingmasing data yang dianalisis. Pengelompokan tersebut menggunakan tingkat A-BC. Tingkat kekuatan rekomendasi A berdasarkan dari bukti ilmiah berbasis pasien yang didapatkan memiliki konsistensi dan kualitas yang baik. Tingkat kekuatan rekomendasi $\mathrm{B}$ berdasarkan bukti ilmiah berbasis pasien yang memiliki kualitas terbatas dan terkadang didapatkan pemaparan bukti yang tidak konsisten. Sedangkan tingkat kekuaran rekomendasi $\mathrm{C}$ berdasarkan pemaparan consensus, kebiasaan praktik sehari-hari, pendapat ahli, hasil kasus serial (Kaminski et al., 2013).

Hasil dari analisis Kaminski T.W. et al., didapatkan pilihan tata laksana pe- 
nanganan cedera sprain pergelangan kaki dengan tingkat kekuatan rekomendasi $\mathrm{A}$ (terbaik) (Kaminski et al., 2013):

1. Medikamentosa Nonsteroidal anti-inflammatory drugs. Pemberian dapat secara per oral atau sediaan topikal. Pemberian sediaan ini bertujuan untuk mengurangi nyeri dan bengkak yang terjadi serta membantu dalam memperbaiki fungsi jangka pendek setelah cedera sprain pergelangan kaki.

2. Dalam tata laksana cedera sprain pergelangan kaki derajat 1 atau 2, penerapan rehabilitasi fungsional akan memberikan hasil yang lebih efektif dibandingkan immobilisasi.

3. Latihan keseimbangan sebaiknya dimasukkan dalam program rehabilitasi dan manajemen lebih lanjut untuk mengurangi angka kejadian cedera kembali pada cedera sprain pergelangan kaki.

Standar awal penatalaksanaan cedera sprain pergelangan kaki adalah dengan melakukan rehabilitasi fungsional. Program tersebut meliputi stabilisasi pergelangan kaki (bisa dengan penggunaan brace, taping, dan lain-lain) yang dikombinasikan dengan latihan weight-bearing secara progresif. Dari berbagai penelitian, penerapan latihan weight-bearing progresif ini memberikan hasil yang lebih baik jika dibandingkan dengan immobilisasi dalam hal pengurangan rasa nyeri dan waktu yang dibutuhkan untuk melakukan kembali aktivitas sehari-hari (Kaminski et al., 2013).

Terapi latihan juga digunakan sebagai metode dalam program rehabilitasi fungsional cedera sprain pergelangan kaki. Tujuan dari penerapan terapi latihan ini adalah untuk mengembalikan ruang lingkup sendi, kekuatan dan fungsi sensorimotor yang mungkin berkurang akibat cedera ke dalam kondisi normal (Kaminski et al., 2013).

Pada pasien cedera sprain pergelangan kaki yang dialaminya terjadi saat kaki mendarat dengan sisi lateral dari kaki 
dan menyebabkan cedera sprain inversi.

Pada tipe cedera ini sangat mungkin terjadi

disabilitas mekanis ataupun fungsional

yang bervariasi. Oleh karena itu diperlukan

penanganan yang spesifik untuk memper-

baiki setiap fungsi dari struktur yang

mengalami cedera. Tujuan akhir dari tata

laksana cedera ini adalah mengembalikan

ruang lingkup sendi hingga dalam batas

normal, melatih struktur-struktur kontraktil

diharapkan agar dapat bekerja secara opti-

mal serta mengembalikan kemampuan pro-

prioseptifnya untuk mencegah cedera ber-

ulang (J. Andrews et al., 2012).

Jika disesuaikan dengan kondisi

penderita saat ini, penderita berada dalam

fase subakut. Kondisi tersebut didukung

dengan tidak tampaknya gejala-gejala in-

flamasi pada pemeriksaan fisik inspeksi dan waktu kejadian cedera yang lebih dari

4 minggu sejak penderita datang untuk berkonsultasi dengan dokter spesialis kedokteran olahraga (J. Andrews et al., 2012).

\section{Terapi latihan fisik}

Berdasarkan kedua manuskrip tersebut (Kaminski et al., 2013; Terada et al., 2013) dan panduan protokol terapi sesuai tahapan fase cedera sprain pergelangan kaki (J. Andrews et al., 2012) dan disesuaikan dengan kondisi pasien ini maka dibuat program latihan sebagai berikut. Beberapa tipe latihan, antara lain: latihan kebugaran jantung paru, latihan kekuatan dan latihan fleksibilitas.

1. Latihan kebugaran jantung paru

Tabel 1. Deskripsi Latihan Kebugaran Jantung Paru

\begin{tabular}{|r|l|}
\hline & \multicolumn{1}{|c|}{ Deskripsi } \\
\hline Jenis latih an & Ergocycle (sepeda statis) \\
\hline Frekuensi & $3 \mathrm{x}$ seminggu \\
\hline Intensitas & Sedang \\
\hline Durasi & 30 menit \\
\hline
\end{tabular}

2. Latihan fleksibilitas

Latihan fleksibilitas dilakukan awal dan akhir sesi latihan fisik kebugaran jantung paru dan kekuatan otot. Latihan fleksibilitas ini dilakukan dengan peregangan statis untuk arah gerak dorsofleksi, plantar plantarfleksi, inversi dan eversi. Pada peregangan ini setiap gerakan dilakukan 2 kali untuk 
setiap arah geraknya. Dan setiap gerak-

an dilakukan penahanan posisi pada

ruang lingkup sendi maksimal yang

dapat ditolerir oleh pasien selama 10

detik.

3. Latihan kekuatan dan lainnya

Latihan kekuatan ini spesifik untuk pasien ini yang diterapkan pada fase subakut dengan target hingga minggu keempat. Latihan kekuatan direncanakan untuk dilakukan sebanyak 3x seminggu dengan penjabaran yang dapat dilihat pada tabel 2 (untuk masing-masing kaki kanan dan kaki kiri) (James Andrews et al., 2012).

Tabel 2. Contoh Perencanaan Latihan Kekuatan

\begin{tabular}{|c|l|l|c|c|c|}
\hline No & \multicolumn{1}{|c|}{ Jenis latih an } & \multicolumn{1}{|c|}{ Beb an } & Set & Repetisi & Keterangan \\
\hline 1 & Alphabet ROM & Bodyweight & 2 & - & Huruf A s.d. Z \\
\hline 2 & $\begin{array}{l}\text { Four direction } \\
\text { surgical tubing } \\
\text { exercises }\end{array}$ & Light tubing & 2 & 10 & \\
\hline 3 & Heel raises & Bodyweight & 2 & 10 & \\
\hline 4 & Toe raises & Bodyweight & 2 & 10 & \\
5 & Tubing side steps & Light tubing & 2 & 10 & \\
\hline 6 & Stork stands & Bodyweight & 2 & - & Tahan 10 detik \\
\hline
\end{tabular}

Ketiga jenis latihan fisik di atas dilakukan dalam 1 sesi dengan urutan latihan kelenturan, latihan daya tahan jantung paru dan latihan kekuatan otot. Di akhir sesi latihan kembali ditutup dengan melakukan latihan kelenturan. Rancana latihan pada peresepan diatas akan dilakukan pada 4 minggu dan dilakukan penyesuaian dengan melihat keteraturan pasien menjalani program tersebut.

Peregangan statis yang menjadi bagian dari program terapi latihan (kombinasi latihan peregangan statis, krioterapi, latihan penguatan dan latihan proprioseptif) di rumah mempunyai efek pada perbaikan ruang lingkup sendi dorsofleksi pada cedera sprain pergelangan kaki. Ke- 
terbatasan ruang lingkup sendi dorsofleksi biasanya terjadi karena kekakuan otot gastrocnemius. Namun pada kasus cedera sprain pergelangan kaki akut, kekakuan struktur kompleks otot gastrocnemiussoleus tidak terjadi dalam jarak waktu singkat setelah kejadian. Biasanya kekakuan yang terjadi merupakan respon adaptif dari immobilisasi dan hasil dari gaya berjalan yang terganggu (Terada et al., 2013).

Berdasarkan kedua pustaka yang didapatkan pilihan utama pencegahan cedera berulang pada pasien dengan keluhan sprain pergelangan kaki adalah terapi latihan fisik. Salah satu jenis latihan yang menjadi bagian dari program terapi latihan fisik adalah latihan proprioseptif. Pada dasarnya yang dimaksud dengan proprioseptif adalah kemampuan fungsional sensorik yang dapat merasakan rangsang berupa rangsangan gerakan pasif maupun gerakan aktif, posisi dan merasakan adanya pembebanan berserta arah gaya (J. Andrews et al., 2012). Dikemukakan resep latihan fisik yang komprehensif akan memberikan hasil terbaik dalam proses terapi pada kondisi seperti ini serta dalam konteks pencegahan cedera berulang.

Resep terapi latihan yang disarankan pada pasien ini adalah latihan peregangan, latihan kekuatan dan juga latihan propioseptif menjadi prioritas. Terapi latihan fisik disarankan untuk dilakukan secara teratur dan hingga penderita dinyatakan sudah siap untuk kembali melakukan latihan fisiknya (Kaminski et al., 2013; Terada et al., 2013).

\section{KESIMPULAN}

Dari hasil penelusuran pustaka, telaah kritis, dan diskusi bisa dibuktikan bahwa terapi pilihan pada pasien dengan keluhan cedera sprain pada pergelangan kaki adalah terapi latihan fisik. Latihan fisik yang harus dilakukan oleh pasien adalah latihan daya tahan jantung paru, latihan kelenturan dan latihan kekuatan otot. Namun perlu diperhatikan pada peresepan latihan fisik setiap pasien akan ber- 
beda disesuaikan dengan kondisi dan kea-

daan masing-masing individunya. Program

latihan fisik tersebut harus dilakukan hing-

ga pasien benar-benar siap untuk kembali

berolahraga. Dengan menjalankan program

latihan fisik tersebut maka diharapkan

hasil yang optimal dalam proses penyem-

buhan dan pencegahan cedera berulang.

\section{DAFTAR PUSTAKA}

Andrews, J., Harrelson, G., \& Wilk, K. (2012). Physical rehabilitation of the injured athlete. Phildelphia: Elvesier.

Bowker, S., et al. (2016). Neural excitability and joint laxity in chronic ankle instability, coper, and control groups. Journal of Athletic Training,51(4), 336-343.

Gribble, P.A., et al. (2014). Selection criteria for patients with chronic ankle instability in controlled research: a position statement of the international ankle consortium. Journal of Athletic Training, 49(1), 121-127.
Hall, E.A., et al. (2015) Strength-training protocols to improve deficits in participants with chronic ankle instability: a randomized controlled trial. Journal of Athletic Training, 50(1), 36-44.

Kaminski, T.W., et al. (2013) National athletic trainers' association position statement: conservative management and prevention of ankle sprains in athletes. Journal of Athletic Training, 48(4), 528-545.

Ktaiche, J., Bassal, A., \& Kalach, A. (2015). Validity of proprioceptive rehabilitation for ankle instability based on freeman board training. European Scientific Journal, 7881(7), 370-388.

Lin, C.C., Delahunt, E., \& King E. (2012). Neuromuscular training for chronic ankle instability. Physical Therapy, 92(8), 987-992.

Silbernagel, K.G., et al. (2007). Full symptomatic recovery does not ensure full recovery of muscle tendon function in patients with achilles tendinopathy. Br J Sports Med, 41, 276-280.

Terada, M., Pietrosimone, B.G., \& Gribble, P.A. (2013). Therapeutic interventions for increasing ankle dorsiflexion after ankle sprain: a systematic review. Journal of Athletic Training, 48(5), 696-709. 